\title{
Spinal Pedicle Morphometry using Multidetector CT-An experience from the Indian Subcontinent
}

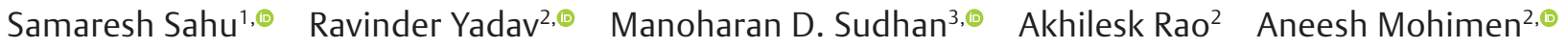 \\ ${ }^{1}$ Department of Radiodiagnosis \& Imaging, Armed Forces Medical \\ College, Pune, India \\ 2Department of Imaging \& Interventional Radiology, Command \\ Hospital Air Force, Agram Post, Bengaluru, India \\ ${ }^{3}$ Department of Neurosurgery, Indian Naval Hospital Ship Asvini, \\ Colaba, Mumbai, India

\begin{abstract}
Address for correspondence Samaresh Sahu, Department of Radiodiagnosis \& Imaging, Armed Forces Medical College, Old Sholapur Road, Pune 560007, India (e-mail: sahu.samaresh@gmail.com).
\end{abstract} \\ Indian J Neurosurg 2022;11:19-29
}

Abstract

Keywords
- spinal pedicle
- multidetector CT scan
- morphometry
- lumbar spine

Introduction For safe pedicle screws placement, knowledge of pedicle morphometry is essential, because an inconsistency between pedicle width and the screw diameter may lead to severe complications like nerve, vessel or visceral injuries.

Objectives To study the spinal pedicle width and height of lumbar spine, using multidetector $\mathrm{CT}$ (MDCT), among the Indian population. To study the spinal pedicle angulation of lumbar spine, using MDCT, among the Indian population.

Method The study was conducted at a tertiary care multispecialty hospital. In the present study, a total of 321 patients were included, who underwent MDCT scan without contrast at our institution, over a period of 2 years, from May 2017 to May 2019. The study population ( $n=321$ ) was divided into different subgroups on the basis of the age. The data was taken from the workstation. Comparison was made separately between each subgroup.

Results In our subset of population, the 10 to 90 years age group, pedicle dimensions are as follow: The pedicle diameter from $L 1$ to $L 5$ is 4.46 to $11.92 \mathrm{~mm}$. The pedicle height from $L 1$ to $L 5$ is 7.38 to $11.01 \mathrm{~mm}$. The pedicle axial angulation from L1 to $L 5$ is 22.27 to 36.08 degree. The pedicle lateral angulation from $L 1$ to $L 5$ is 16.12 to 22.47 degree.

Conclusion Knowledge of the pedicle morphometry (pedicle width, height and angulation) of lumbar spine will help the neurosurgeons standardize the size of pedicle screws which is required for spinal fixation surgery at various lumbar vertebra levels.

\section{Introduction}

Backache and neck pain has been the scourge of mankind ever since it assumed the erect posture. The pain has troubled patients and treating doctors alike. Pinpointing the cause of backache and neck pain and treating it successfully has been their constant endeavor.

The sole bridge between the posterior, middle, and anterior columns is pedicle. Hence, pedicle screws traverse all three columns and can rigidly stabilize both the ventral and dorsal aspects of the spine. Performing

published online May 13, 2021
DOI https://doi.org/ 10.1055/s-0040-1719203 ISSN 2277-954X. pedicle screw fixation is technically challenging. ${ }^{1}$ The key to successful surgery involves possessing clear knowledge of intracanal anatomy and the location of the pedicle. ${ }^{2} \mathrm{~A}$ detailed knowledge of pedicle size and dimensions is crucial while using the pedicle to gain hold and strength of the vertebra. The sizes of the screws used in surgery must take pedicle dimensions into consideration. ${ }^{3}$

Intraoperative complications for the pedicle screw fixation include screw misdirection and pedicle fracture. ${ }^{4}$ The stability of the pedicle screw and its pullout strength depend on the integrity of the pedicle and 
the vertebral body even though larger screw sizes are preferred as they are stronger and give better results. The deciding factor in screw selection is the minimum width of the pedicle.

The morphometric characteristics of the vertebral pedicle are valuable for preoperative procedure planning and in the design and manufacture of pedicle screws. ${ }^{5}$ Knowledge of such morphometric characteristics is important for the surgeon to prevent injuries to the pedicle cortex, meninges, nerve roots, joint facets, viscera or adjacent vascular structures due to misplacement or improper orientation of the screws. ${ }^{6,7}$

Previous studies have resorted to the use of axial slices in CT to determine the cortical and endosteal pedicle widths of lumbar pedicles. However, recently, it has been established that due to the oval morphology of the lumbar pedicle in the coronal section and the normal vertebral pedicle inclination in relation to the horizontal plane, the pedicle width results obtained from these studies may not match the actual minimum pedicle diameter and may lead to inadequate identification of the morphometric features of the pedicle. ${ }^{8}$

The present study was done at our tertiary care institute to assess the spinal pedicle morphometry (pedicle width, height and angulation) of lumbar spine using multidetector CT (MDCT) scan, so as to develop a standard value for the Indian population.

\section{Aim}

To study the morphometry of lumbar spine pedicles for neurosurgical intervention by using noninvasive MDCT, in order to standardize the size of pedicle screws at various lumbar levels and across different age groups.

\section{Objectives}

1. To study the spinal pedicle width and height of lumbar spine, using MDCT, among the Indian population.

2. To study the spinal pedicle angulation of lumbar spine, using MDCT, among the Indian population.

\section{Materials and Methods}

a) Patient Population

After being approved by the ethical committee board at our institution, we prospectively included patients who were referred to us for lumbar spine pedicle morphology evaluation using 16 slice scanner (Brilliance 16, Philips; Netherlands) at our institution over a period of 2 years, extending from May 2017 to May 2019.

A total of 321 cases were included in the study. The inclusion of cases was on the basis of referral from neurosurgical outpatient and patients who were planned for surgery. All these patients were scanned after obtaining an informed consent, and all patients who had undergone noncontrast CT abdomen were also included in the dataset. All the cases of lumbar spine operated or fracture were excluded from the study.

\section{b) Data Collection}

Data was evaluated and reconstructed at our CT workstation as per the protocol. The study was done at our tertiary care hospital set up to assess the spinal pedicle morphometry (pedicle width, height and angulation) of lumbar spine, so as to develop a standard value for the Indian population. The aim was to standardize the size of pedicle screws that is required at various lumbar vertebra levels and vary it as per the sex and age of the patient. All patients who presented with features of spondylolysis on radiograph and planned for pedicle fixation screws were included in the study. Each scan was evaluated by a radiologist with experience of more than 10 years after being evaluated by a final-year radiology resident who was well-trained to calculate the morphometric values of pedicle.

The transverse diameter and angulation of each side of pedicle was measured as depicted in -Figs. $\mathbf{1}$ and $\mathbf{2}$. The height of each pedicle and the sagittal angulation was measured as depicted in - Figs. 3 and $\mathbf{4}$. For sagittal angulation, on each side, images were reconstructed in oblique sagittal plane, where the maximum height of pedicle was observed. This was done to provide the most anatomic orientation to the pedicle in relation to the vertebral body.

The data was taken from the workstation. Comparison was made separately between each subgroup.

\section{Statistical Method}

Descriptive analysis was performed by mean and standard deviation for quantitative variables, ad frequency and proportion for categorical variables. Data was also represented using appropriate diagrams like bar diagram, pie diagram, and box plots.

\section{Results}

Among the study population ( $n=321), 34(10.6 \%)$ participants were aged between 10 to 20 years, 49 (15.30\%) participants were aged between 21 to 30 years,

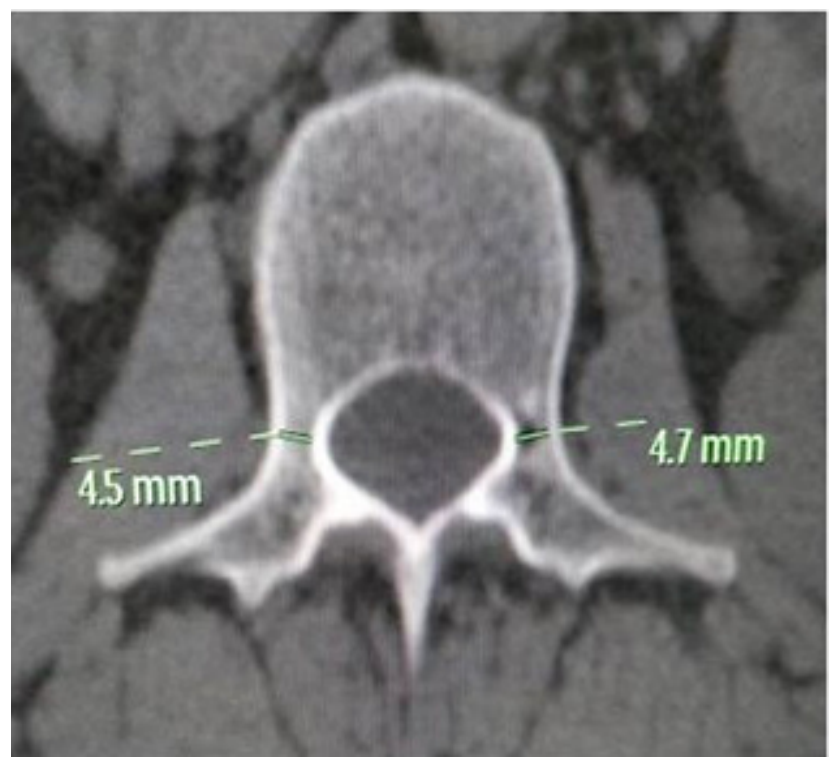

Fig. 1 Showing the measurement of inner cancellous axial diameter of $L 2$ vertebra. 


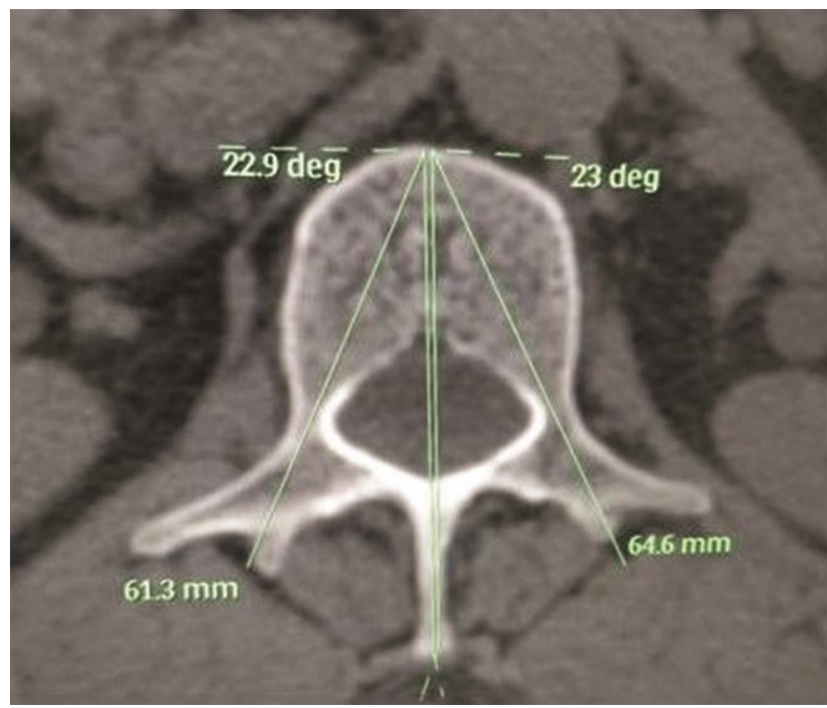

Fig. 2 Showing the axial angle formed by the longitudinal trajectory of the right- and left-sided pedicles at the axis of the $L 2$ vertebra.

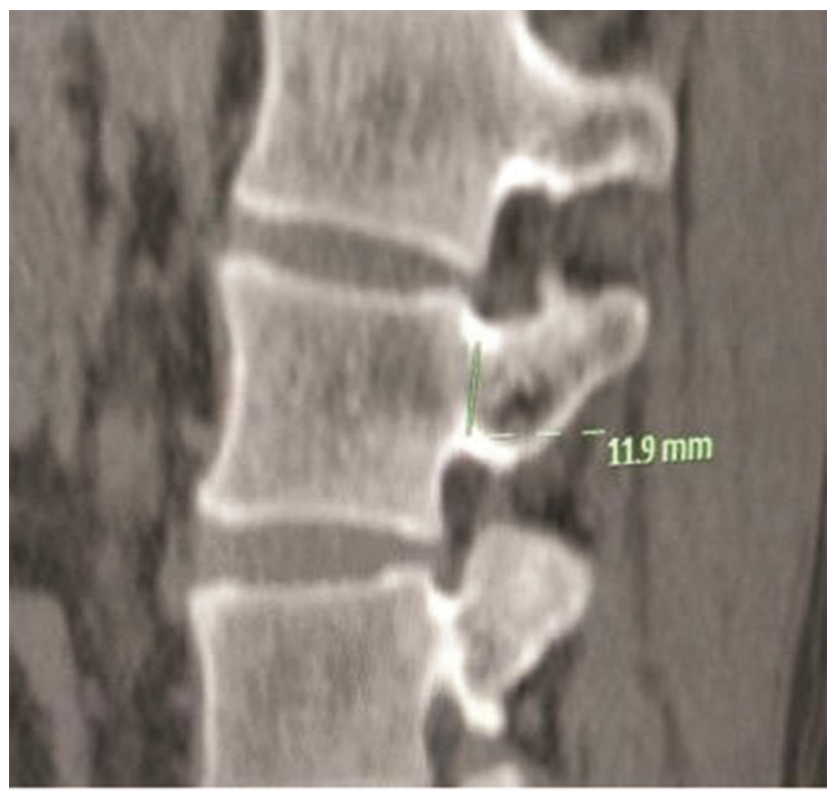

Fig. 3 Showing the inner cancellous pedicle height of L2 vertebra.

44 (13.7\%) participants were aged between 31 to 40 years, $51(15.9 \%)$ participants were aged between 41 to 50 years, $54(16.8 \%)$ participants were aged between 51 to 60 years, 45 (14\%) participants were aged between 61 to 70 years, 30 (9.3\%) participants were aged between 71 to 80 years, and $14(4.4 \%)$ participants were aged between 81 to 90yrs. Our study comprised of $67.6 \%$ male and $32.4 \%$ female patients.

\section{In the 10 to 20 Years Age Group}

In the age group of 10 to 20 years $(n=34)$, the mean axial diameter of the pedicle varied from 6.18 to $11.46 \mathrm{~mm}$ on the right and 5.81 to $11.67 \mathrm{~mm}$ on the left side. The mean height of pedicle varied from 9.42 to $9.26 \mathrm{~mm}$ on the right and 9.22 to $9.14 \mathrm{~mm}$ on the left side - Table $\mathbf{1}$.

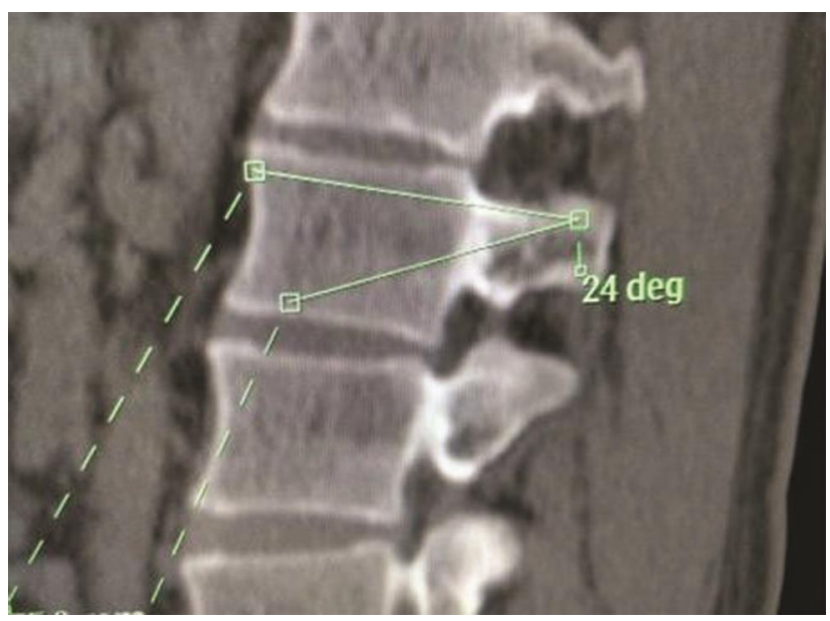

Fig. 4 Showing the pedicle body lateral angulation of the right sided pedicle of the $L 2$ vertebra.

In the age group of 10 to 20 years $(n=34)$, the mean transverse angulation of the pedicle varied from 21.27 to 34.69 degrees on the right and 20.9 to 35.29 degrees on the left side. The mean sagittal angulation of pedicle varied from 19.02 to 18.56 degrees on the right and 18.38 to 18.69 degrees on the left side - Table 2 .

\section{In the 21 to 30 Years Age Group}

In the age group of 21 to 30 years ( $n=49$ ), the mean axial diameter of the pedicle varied from 5.59 to $11.41 \mathrm{~mm}$ on the right and 5.54 to $11.63 \mathrm{~mm}$ on the left side. The mean height of pedicle varied from 10.7 to $9.13 \mathrm{~mm}$ on the right and 10.45 to $8.99 \mathrm{~mm}$ on the left side - Table 3 .

In the age group of 21 to 30 years $(n=49)$, the mean transverse angulation of the pedicle varied from 22.47 to 34.66 degrees on the right and 22.37 to 34.75 degrees on the left side. The mean sagittal angulation of pedicle varied from 21.13 to 19.94 degrees on the right and 21.01 to 19.65 degrees on the left side - Table 4 .

\section{In the Age Group of 31 to 40 Years}

In the age group of 31 to 40 years $(n=44)$, the mean axial diameter of the pedicle varied from 5.89 to $12.67 \mathrm{~mm}$ on the right and 6.01 to $12.74 \mathrm{~mm}$ on the left side. The mean height of pedicle varied from 11.01 to $9.16 \mathrm{~mm}$ on the right and 10.85 to $9.28 \mathrm{~mm}$ on the left side - Table $\mathbf{5}$.

In the age group of 31 to 40 years $(n=44)$, the mean transverse angulation of the pedicle varied from 22.97 to 35.89 degrees on the right and 22.92 to 35.78 degrees on the left side. The mean lateral angulation of pedicle varied from 22.24 to 21.9 degrees on the right and 22.06 to 21.23 degrees on the left side - Table 6 .

\section{In the Age Group of $\mathbf{4 1}$ to 50 Years}

In the age group of 41 to 50 years $(n=51)$, the mean axial diameter of the pedicle varied from 5.4 to $11.89 \mathrm{~mm}$ on the right and 5.29 to $11.49 \mathrm{~mm}$ on the left side. The mean height 
22 Spinal Pedicle Morphometry Sahu et al.

Table 1 Descriptive analysis of pedicle diameter $(\mathrm{mm})$ and height $(\mathrm{mm})$ in study population $(\mathrm{N}=34)$

\begin{tabular}{|c|c|c|c|c|c|c|}
\hline \multirow[t]{2}{*}{ Parameter } & \multirow{2}{*}{$\begin{array}{l}\text { Diameter } \\
\text { mean } \pm \text { SD }(\mathrm{mm})\end{array}$} & \multicolumn{2}{|c|}{$95 \% \mathrm{Cl}$} & \multirow{2}{*}{$\begin{array}{l}\text { Height } \\
\text { mean } \pm \text { SD }(\mathrm{mm})\end{array}$} & \multicolumn{2}{|c|}{$95 \% \mathrm{Cl}$} \\
\hline & & Lower & Upper & & Lower & Upper \\
\hline L1 right & $6.18 \pm 0.62$ & 5.96 & 6.39 & $9.42 \pm 0.2$ & 9.34 & 9.49 \\
\hline L2 right & $5.98 \pm 0.58$ & 5.78 & 6.18 & $9.82 \pm 0.22$ & 9.75 & 9.90 \\
\hline L3 right & $8.21 \pm 0.65$ & 7.99 & 8.44 & $9.75 \pm 0.16$ & 9.70 & 9.81 \\
\hline L4 right & $8.43 \pm 0.1$ & 8.39 & 8.46 & $8.11 \pm 0.16$ & 8.05 & 8.16 \\
\hline L5 right & $11.46 \pm 0.3$ & 11.36 & 11.57 & $9.26 \pm 0.22$ & 9.18 & 9.33 \\
\hline L1 left & $5.81 \pm 0.48$ & 5.64 & 5.98 & $9.29 \pm 0.21$ & 9.22 & 9.36 \\
\hline L2 left & $5.65 \pm 0.42$ & 5.510 & 5.80 & $10.36 \pm 0.25$ & 10.27 & 10.44 \\
\hline L3 left & $7.92 \pm 0.65$ & 7.70 & 8.15 & $8.94 \pm 0.37$ & 8.81 & 9.07 \\
\hline L4 left & $8.26 \pm 0.16$ & 8.21 & 8.32 & $7.67 \pm 0.33$ & 7.55 & 7.79 \\
\hline L5 left & $11.67 \pm 0.27$ & 11.58 & 11.76 & $9.32 \pm 0.5$ & 9.14 & 9.49 \\
\hline
\end{tabular}

Table 2 Descriptive analysis of pedicle body angulation transverse (TA) and sagittal (degree) in study population ( $N=34$ )

\begin{tabular}{|c|c|c|c|c|c|c|}
\hline \multirow[t]{2}{*}{ Parameter } & \multirow{2}{*}{$\begin{array}{l}\text { Axial } \\
\text { mean } \pm \text { SD }(\mathrm{mm})\end{array}$} & \multicolumn{2}{|c|}{$95 \% \mathrm{Cl}$} & \multirow{2}{*}{$\begin{array}{l}\text { Lateral } \\
\text { mean } \pm \text { SD (mm) }\end{array}$} & \multicolumn{2}{|c|}{$95 \% \mathrm{Cl}$} \\
\hline & & Lower & Upper & & Lower & Upper \\
\hline L1 right & $21.27 \pm 1.07$ & 20.90 & 21.64 & $19.02 \pm 0.53$ & 18.84 & 19.20 \\
\hline L2 right & $20.99 \pm 0.82$ & 20.70 & 21.28 & $18.9 \pm 0.81$ & 18.61 & 19.18 \\
\hline L3 right & $24.4 \pm 1.05$ & 24.03 & 24.76 & $18.39 \pm 1.33$ & 17.93 & 18.86 \\
\hline L4 right & $26.69 \pm 0.7$ & 26.45 & 26.93 & $17.69 \pm 1.01$ & 17.33 & 18.04 \\
\hline L5 right & $34.69 \pm 0.37$ & 34.56 & 34.81 & $18.56 \pm 1.92$ & 17.89 & 19.23 \\
\hline L1 left & $20.92 \pm 1.05$ & 20.55 & 21.28 & $18.38 \pm 0.86$ & 18.08 & 18.68 \\
\hline L2 left & $21.39 \pm 0.64$ & 21.16 & 21.61 & $17.87 \pm 1.37$ & 17.39 & 18.35 \\
\hline L3 left & $23.83 \pm 1.07$ & 23.45 & 24.20 & $18.03 \pm 1.67$ & 17.45 & 18.61 \\
\hline L4 left & $26.27 \pm 0.95$ & 25.94 & 26.60 & $17.63 \pm 1.02$ & 17.27 & 17.98 \\
\hline L5 left & $35.29 \pm 0.24$ & 35.20 & 35.37 & $18.69 \pm 1.58$ & 18.14 & 19.24 \\
\hline
\end{tabular}

Table 3 Descriptive analysis of pedicle diameter and height in study population $(N=49)$

\begin{tabular}{|c|c|c|c|c|c|c|}
\hline \multirow[t]{2}{*}{ Parameter } & \multirow{2}{*}{$\begin{array}{l}\text { Diameter } \\
\text { mean } \pm S D \\
(\mathrm{~mm})\end{array}$} & \multicolumn{2}{|c|}{$95 \% \mathrm{Cl}$} & \multirow{2}{*}{$\begin{array}{l}\text { Height } \\
\text { mean } \pm S D \\
(\mathrm{~mm})\end{array}$} & \multicolumn{2}{|c|}{$95 \% \mathrm{Cl}$} \\
\hline & & Lower & Upper & & Lower & Upper \\
\hline L1 right & $5.59 \pm 0.91$ & 5.33 & 5.85 & $10.7 \pm 1.3$ & 10.33 & 11.07 \\
\hline L2 right & $5.58 \pm 1.13$ & 5.25 & 5.90 & $10.48 \pm 1.05$ & 10.18 & 10.78 \\
\hline L3 right & $6.92 \pm 1.28$ & 6.55 & 7.29 & $9.99 \pm 0.9$ & 9.73 & 10.25 \\
\hline L4 right & $8.08 \pm 1.35$ & 7.69 & 8.47 & $9.12 \pm 1.12$ & 8.80 & 9.44 \\
\hline L5 right & $11.41 \pm 0.36$ & 11.02 & 11.80 & $9.13 \pm 1.02$ & 8.84 & 9.42 \\
\hline L1 left & $5.54 \pm 0.93$ & 5.27 & 5.80 & $10.45 \pm 1.18$ & 10.11 & 10.79 \\
\hline L2 left & $5.62 \pm 1.02$ & 5.33 & 5.91 & $10.35 \pm 1.06$ & 10.05 & 10.65 \\
\hline L3 left & $7.01 \pm 1.1$ & 6.7 & 7.33 & $10.04 \pm 0.82$ & 9.80 & 10.27 \\
\hline L4 left & $8.08 \pm 1.19$ & 7.74 & 8.42 & $9.16 \pm 1.31$ & 8.78 & 9.54 \\
\hline L5 left & $11.63 \pm 0.35$ & 11.24 & 12.01 & $8.99 \pm 1.07$ & 8.68 & 9.30 \\
\hline
\end{tabular}


Table 4 Descriptive analysis of pedicle body angulation transverse (TA) and sagittal in study population $(N=49)$

\begin{tabular}{|l|l|l|l|l|l|l|}
\hline \multirow{2}{*}{ Parameter } & Axial & \multicolumn{2}{|c|}{$95 \% \mathrm{Cl}$} & Lateral & \multicolumn{2}{c|}{ 95\% Cl } \\
& mean \pm SD & \multicolumn{1}{|c|}{ Lower } & Upper & mean \pm SD & Lower & Upper \\
\hline L1 right & $22.47 \pm 1.31$ & 22.10 & 22.85 & $21.13 \pm 2.41$ & 20.43 & 21.82 \\
\hline L2 right & $22.91 \pm 1.35$ & 22.52 & 23.29 & $20.43 \pm 1.92$ & 19.88 & 20.98 \\
\hline L3 right & $24.93 \pm 1.61$ & 24.47 & 25.39 & $21 \pm 3.38$ & 20.03 & 21.97 \\
\hline L4 right & $28.44 \pm 1.55$ & 27.99 & 28.88 & $19.67 \pm 2.82$ & 18.86 & 20.48 \\
\hline L5 right & $34.66 \pm 2.29$ & 34.00 & 35.32 & $19.94 \pm 2.77$ & 19.15 & 20.74 \\
\hline L1 left & $22.37 \pm 1.36$ & 21.98 & 22.76 & $21.01 \pm 2.45$ & 20.31 & 21.71 \\
\hline L2 left & $22.81 \pm 1.23$ & 22.46 & 23.16 & $20.38 \pm 2.09$ & 19.78 & 20.98 \\
\hline L3 left & $24.91 \pm 1.59$ & 24.45 & 25.37 & $21.22 \pm 3.5$ & 20.22 & 22.23 \\
\hline L4 left & $28.42 \pm 1.65$ & 27.94 & 28.89 & $19.29 \pm 2.93$ & 18.45 & 20.13 \\
\hline L5 left & $34.75 \pm 2.22$ & 34.12 & 35.39 & $19.65 \pm 3.03$ & 18.77 & 20.52 \\
\hline
\end{tabular}

Table 5 Descriptive analysis of pedicle diameter and height in study population $(N=44)$

\begin{tabular}{|l|l|l|l|l|l|l|}
\hline \multirow{2}{*}{ Parameter } & Diameter & \multicolumn{2}{|c|}{$95 \% \mathrm{Cl}$} & Height & \multicolumn{2}{|c|}{ 95\% Cl } \\
\cline { 3 - 7 } & $\begin{array}{l}\text { mean } \pm \text { SD } \\
\text { (mm) }\end{array}$ & Lower & Upper & $\begin{array}{l}\text { mean } \pm \text { SD } \\
(\mathbf{m m})\end{array}$ & Lower & Upper \\
\hline L1 right & $5.89 \pm 0.83$ & 5.64 & 6.14 & $11.01 \pm 1.31$ & 10.61 & 11.41 \\
\hline L2 right & $5.89 \pm 0.74$ & 5.66 & 6.11 & $10.18 \pm 1.35$ & 9.77 & 10.59 \\
\hline L3 right & $7.21 \pm 0.91$ & 6.93 & 7.49 & $10.21 \pm 0.93$ & 9.93 & 10.49 \\
\hline L4 right & $8.93 \pm 1.68$ & 8.41 & 9.44 & $9.86 \pm 1.56$ & 9.39 & 10.34 \\
\hline L5 right & $12.67 \pm 2.12$ & 12.02 & 13.31 & $9.16 \pm 0.87$ & 8.89 & 9.42 \\
\hline L1 left & $6.01 \pm 0.82$ & 5.76 & 6.26 & $10.85 \pm 1.12$ & 10.51 & 11.19 \\
\hline L2 left & $6.14 \pm 0.73$ & 5.92 & 6.36 & $10.06 \pm 1.26$ & 9.67 & 10.44 \\
\hline L3 left & $7.13 \pm 0.96$ & 6.84 & 7.42 & $10.2 \pm 0.97$ & 9.90 & 10.49 \\
\hline L4 left & $8.93 \pm 1.49$ & 8.48 & 9.39 & $9.74 \pm 1.46$ & 9.30 & 10.19 \\
\hline L5 left & $12.74 \pm 2.04$ & 12.12 & 13.36 & $9.28 \pm 0.89$ & 9.01 & 9.55 \\
\hline
\end{tabular}

Table 6 Descriptive analysis of pedicle body angulation transverse (TA) and sagittal in study population $(N=44)$

\begin{tabular}{|c|c|c|c|c|c|c|}
\hline \multirow[t]{2}{*}{ Parameter } & \multirow{2}{*}{$\begin{array}{l}\text { Axial } \\
\text { mean } \pm S D \\
(\mathrm{~mm})\end{array}$} & \multicolumn{2}{|c|}{$95 \% \mathrm{Cl}$} & \multirow{2}{*}{$\begin{array}{l}\text { Lateral } \\
\text { mean } \pm \text { SD } \\
(\mathrm{mm})\end{array}$} & \multicolumn{2}{|c|}{$95 \% \mathrm{Cl}$} \\
\hline & & Lower & Upper & & Lower & Upper \\
\hline L1 right & $22.97 \pm 1.21$ & 22.60 & 23.34 & $22.24 \pm 2.93$ & 21.35 & 23.13 \\
\hline L2 right & $23.45 \pm 1.48$ & 23.00 & 23.90 & $21.45 \pm 1.67$ & 20.95 & 21.96 \\
\hline L3 right & $25.3 \pm 1.53$ & 24.83 & 25.76 & $21.36 \pm 2.13$ & 20.71 & 22.01 \\
\hline L4 right & $28.61 \pm 1.37$ & 28.19 & 29.03 & $20 \pm 2.25$ & 19.32 & 20.68 \\
\hline L5 right & $35.89 \pm 2.89$ & 35.01 & 36.77 & $21.9 \pm 2.78$ & 21.05 & 22.74 \\
\hline L1 left & $22.92 \pm 1.2$ & 22.56 & 23.29 & $22.06 \pm 2.56$ & 21.28 & 22.83 \\
\hline L2 left & $23.18 \pm 1.5$ & 22.72 & 23.63 & $21.56 \pm 1.76$ & 21.02 & 22.09 \\
\hline L3 left & $25.46 \pm 1.71$ & 24.94 & 25.98 & $21.16 \pm 2.13$ & 20.51 & 21.81 \\
\hline L4 left & $28.68 \pm 1.33$ & 28.27 & 29.08 & $20.1 \pm 2.29$ & 19.40 & 20.79 \\
\hline L5 left & $35.78 \pm 3.05$ & 34.85 & 36.71 & $21.23 \pm 2.58$ & 20.44 & 22.01 \\
\hline
\end{tabular}

of pedicle varied from 10.8 to $8.57 \mathrm{~mm}$ on the right and 10.98 to $8.51 \mathrm{~mm}$ on the left side $\boldsymbol{\sim}$ Table 7 .

In the age group of 41 to 50 years $(n=51)$, the mean transverse angulation of the pedicle varied from 22.78 to 36.08 degrees on the right and 22.7 to 36.18 degrees on the left side. The mean lateral angulation of pedicle varied from 22.71 to
22.47 degrees on the right and 21.48 to 21.38 degrees on the left side - Table 8.

\section{In the Age Group of 51 to 60 Years}

In the age group of 51 to 60 years $(n=54)$, the mean axial diameter of the pedicle varied from 5.88 to $11.92 \mathrm{~mm}$ on the 
right and 5.84 to $11.53 \mathrm{~mm}$ on the left side. The mean height of pedicle varied from 11.01 to $9 \mathrm{~mm}$ on the right and 10.89 to $8.85 \mathrm{~mm}$ on the left side - Table $\mathbf{9}$.

In the age group of 51 to 60 years $(n=54)$, the mean transverse angulation of the pedicle varied from 23.2 to 32.88 degrees on the right and 23.21 to 32.39 degrees on the left side. The mean sagittal angulation of pedicle varied from 18.27 to 19.1 degrees on the right and 18.34 to 20.09 degrees on the left side - Table $\mathbf{1 0}$.

\section{In the Age Group of 61 to 70 Years}

In the age group of 61 to 70 years $(n=45)$, the mean axial diameter of the pedicle varied from 5.87 to $11.09 \mathrm{~mm}$ on the right and 5.95 to $10.79 \mathrm{~mm}$ on the left side. The mean height of pedicle varied from 10.59 to $8.7 \mathrm{~mm}$ on the right and 10.46 to $8.52 \mathrm{~mm}$ on the left side - Table 11 .

In the age group of 61 to 70 years $(n=45)$, the mean transverse angulation of the pedicle varied from 23.73 to 31.94 degrees on the right and 23.87 to 32.32 degrees on the left side. The mean sagittal angulation of pedicle varied from 17.95 to 17.4 degrees on the right and 17.95 to 17.57 degrees on the left side - Table 12 .

\section{In the Age Group of 71 to 80 Years}

In the age group of 71 to 80 years $(n=30)$, the mean axial diameter of the pedicle varied from 4.9 to $10.37 \mathrm{~mm}$ on the right and 4.7 to $10.49 \mathrm{~mm}$ on the left side. The mean height of pedicle varied from 10.03 to $7.7 \mathrm{~mm}$ on the right and 10.1 to $7.73 \mathrm{~mm}$ on the left side - Table $\mathbf{1 3}$.

In the age group of 71 to 80 years $(n=30)$, the mean transverse angulation of the pedicle varied from 22.6 to 31.99 degrees on the right and 22.07 to 32.45 degrees on the left side. The mean sagittal angulation of pedicle varied from 18.44 to 15.56 degrees on the right and 18.77 to 15.83 degrees on the left side - Table 14 .

\section{In the Age Group of 81 to 90 Years}

In the age group of 81 to 90 years $(n=14)$, the mean axial diameter of the pedicle varied from 4.66 to $10.21 \mathrm{~mm}$ on the right and 4.46 to $10.29 \mathrm{~mm}$ on the left side. The mean height of pedicle varied from 9.78 to $7.49 \mathrm{~mm}$ on the right and 9.49 to $7.38 \mathrm{~mm}$ on the left side - Table 15 .

In the age group of 81 to 60 years $(n=14)$, the mean transverse angulation of the pedicle varied from 22.94 to 32.27 degrees on the right and 22.64 to 32.57 degrees on the left

Table 7 Descriptive analysis of pedicle diameter and height in study population $(N=51)$

\begin{tabular}{|c|c|c|c|c|c|c|}
\hline \multirow[t]{2}{*}{ Parameter } & \multirow{2}{*}{$\begin{array}{l}\text { Diameter } \\
\text { mean } \pm S D \\
(\mathrm{~mm})\end{array}$} & \multicolumn{2}{|c|}{$95 \% \mathrm{Cl}$} & \multirow{2}{*}{$\begin{array}{l}\text { Height } \\
\text { mean } \pm \text { SD } \\
(\mathrm{mm})\end{array}$} & \multicolumn{2}{|c|}{$95 \% \mathrm{Cl}$} \\
\hline & & Lower & Upper & & Lower & Upper \\
\hline L1 right & $5.4 \pm 0.93$ & 5.14 & 5.66 & $10.8 \pm 0.9$ & 10.55 & 11.05 \\
\hline L2 right & $5.71 \pm 0.84$ & 5.47 & 5.94 & $10.2 \pm 0.8$ & 9.97 & 10.42 \\
\hline L3 right & $6.89 \pm 1.08$ & 6.59 & 7.20 & $10.47 \pm 1.04$ & 10.18 & 10.77 \\
\hline L4 right & $8.67 \pm 1.08$ & 8.37 & 8.98 & $9.55 \pm 1.16$ & 9.22 & 9.87 \\
\hline L5 right & $11.58 \pm 1.48$ & 11.16 & 12.00 & $8.57 \pm 0.85$ & 8.33 & 8.81 \\
\hline L1 left & $5.29 \pm 0.97$ & 5.02 & 5.57 & $10.91 \pm 0.92$ & 10.65 & 11.17 \\
\hline L2 left & $5.74 \pm 0.85$ & 5.50 & 5.98 & $10.17 \pm 0.79$ & 9.94 & 10.39 \\
\hline L3 left & $6.76 \pm 1.1$ & 6.45 & 7.07 & $10.2 \pm 1.01$ & 9.92 & 10.49 \\
\hline L4 left & $8.31 \pm 1.22$ & 7.96 & 8.65 & $9.24 \pm 1.04$ & 8.95 & 9.54 \\
\hline L5 left & $11.49 \pm 1.46$ & 11.08 & 11.90 & $8.58 \pm 0.88$ & 8.33 & 8.83 \\
\hline
\end{tabular}

Table 8 Descriptive analysis of pedicle body angulation transverse (TA) and sagittal in study population $(N=51)$

\begin{tabular}{|c|c|c|c|c|c|c|}
\hline \multirow[t]{2}{*}{ Parameter } & \multirow{2}{*}{$\begin{array}{l}\text { Axial } \\
\text { mean } \pm S D \\
(\mathrm{~mm})\end{array}$} & \multicolumn{2}{|c|}{$95 \% \mathrm{Cl}$} & \multirow{2}{*}{$\begin{array}{l}\text { Lateral } \\
\text { mean } \pm \text { SD } \\
(\mathrm{mm})\end{array}$} & \multicolumn{2}{|c|}{$95 \% \mathrm{Cl}$} \\
\hline & & Lower & Upper & & Lower & Upper \\
\hline L1 right & $22.78 \pm 2.36$ & 22.11 & 23.44 & $21.71 \pm 3.4$ & 20.76 & 22.67 \\
\hline L2 right & $23.46 \pm 2.43$ & 22.77 & 24.14 & $19.98 \pm 2.9$ & 19.17 & 20.80 \\
\hline L3 right & $25.15 \pm 1.97$ & 24.59 & 25.70 & $20.86 \pm 2.63$ & 20.11 & 21.60 \\
\hline L4 right & $28.38 \pm 2.46$ & 27.68 & 29.07 & $20.13 \pm 2.37$ & 19.47 & 20.80 \\
\hline L5 right & $36.08 \pm 5.05$ & 34.66 & 37.50 & $22.47 \pm 3.1$ & 21.60 & 23.34 \\
\hline L1 left & $22.7 \pm 2.39$ & 22.03 & 23.37 & $21.48 \pm 3.15$ & 20.59 & 22.36 \\
\hline L2 left & $23.48 \pm 2.41$ & 22.81 & 24.16 & $20.1 \pm 2.86$ & 19.30 & 20.91 \\
\hline L3 left & $25.11 \pm 2.1$ & 24.52 & 25.70 & $20.46 \pm 2.24$ & 19.83 & 21.09 \\
\hline L4 left & $28.27 \pm 2.57$ & 27.54 & 28.99 & $19.31 \pm 2.55$ & 18.59 & 20.03 \\
\hline L5 left & $36.13 \pm 5.2$ & 34.67 & 37.60 & $21.38 \pm 3.46$ & 20.41 & 22.36 \\
\hline
\end{tabular}


side. The mean sagittal angulation of pedicle varied from 18.44 to 16.12 degrees on the right and 18.69 to 16.4 degrees on the left side - Table 16.

\section{Discussion}

Low-back pain is the second most common complaint

Table 9 Descriptive analysis of pedicle diameter and height in study population $(N=54)$

\begin{tabular}{|c|c|c|c|c|c|c|}
\hline \multirow[t]{2}{*}{ Parameter } & \multirow{2}{*}{$\begin{array}{l}\text { Diameter } \\
\text { mean } \pm S D \\
(\mathrm{~mm})\end{array}$} & \multicolumn{2}{|c|}{$95 \% \mathrm{Cl}$} & \multirow{2}{*}{$\begin{array}{l}\text { Height } \\
\text { mean } \pm S D \\
(\mathrm{~mm})\end{array}$} & \multicolumn{2}{|c|}{$95 \% \mathrm{Cl}$} \\
\hline & & Lower & Upper & & Lower & Upper \\
\hline L1 right & $5.88 \pm 1.35$ & 5.51 & 6.25 & $11.01 \pm 1.78$ & 10.52 & 11.49 \\
\hline L2 right & $6.52 \pm 1.66$ & 6.07 & 6.98 & $10.46 \pm 1.68$ & 10.00 & 10.92 \\
\hline L3 right & $7.89 \pm 1.88$ & 7.37 & 8.40 & $10.12 \pm 1.59$ & 9.69 & 10.56 \\
\hline L4 right & $9.1 \pm 1.94$ & 8.57 & 9.63 & $9.53 \pm 1.56$ & 9.10 & 9.95 \\
\hline L5 right & $11.92 \pm 2.74$ & 11.18 & 12.67 & $9 \pm 1.77$ & 8.52 & 9.48 \\
\hline L1 left & $5.84 \pm 1.33$ & 5.47 & 6.20 & $10.89 \pm 1.64$ & 10.45 & 11.34 \\
\hline L2 left & $6.5 \pm 1.75$ & 6.02 & 6.97 & $10.23 \pm 1.48$ & 9.83 & 10.64 \\
\hline L3 left & $7.88 \pm 1.87$ & 7.37 & 8.39 & $9.85 \pm 1.3$ & 9.49 & 10.20 \\
\hline L4 left & $8.97 \pm 2.13$ & 8.39 & 9.55 & $9.33 \pm 1.19$ & 9.01 & 9.66 \\
\hline L5 left & $11.53 \pm 2.07$ & 10.97 & 12.10 & $8.85 \pm 1.7$ & 8.38 & 9.31 \\
\hline
\end{tabular}

Table 10 Descriptive analysis of pedicle body angulation transverse (TA) and sagittal in study population $(N=54)$

\begin{tabular}{|c|c|c|c|c|c|c|}
\hline \multirow[t]{2}{*}{ Parameter } & \multirow{2}{*}{$\begin{array}{l}\text { Axial } \\
\text { mean } \pm \text { SD }\end{array}$} & \multicolumn{2}{|c|}{$95 \% \mathrm{Cl}$} & \multirow{2}{*}{$\begin{array}{l}\text { Lateral } \\
\text { mean } \pm \text { SD }\end{array}$} & \multicolumn{2}{|c|}{$95 \% \mathrm{Cl}$} \\
\hline & & Lower & Upper & & Lower & Upper \\
\hline L1 right & $23.2 \pm 1.97$ & 22.66 & 23.73 & $18.27 \pm 2.66$ & 17.54 & 18.99 \\
\hline L2 right & $23.03 \pm 1.71$ & 22.57 & 23.50 & $17.99 \pm 2.96$ & 17.18 & 18.80 \\
\hline L3 right & $25.13 \pm 2.19$ & 24.54 & 25.73 & $17.75 \pm 2.91$ & 16.96 & 18.55 \\
\hline L4 right & $27.83 \pm 2.55$ & 27.14 & 28.53 & $18.17 \pm 3.07$ & 17.33 & 19.01 \\
\hline L5 right & $32.88 \pm 4.74$ & 31.59 & 34.17 & $19.1 \pm 5.25$ & 17.67 & 20.53 \\
\hline L1 left & $23.21 \pm 1.91$ & 22.69 & 23.73 & $18.34 \pm 2.72$ & 17.59 & 19.08 \\
\hline L2 left & $23.39 \pm 1.56$ & 22.97 & 23.82 & $18.22 \pm 2.93$ & 17.41 & 19.02 \\
\hline L3 left & $25.16 \pm 2.1$ & 24.59 & 25.73 & $17.73 \pm 2.73$ & 16.98 & 18.48 \\
\hline L4 left & $27.64 \pm 2.65$ & 26.92 & 28.36 & $18.44 \pm 3.04$ & 17.60 & 19.27 \\
\hline L5 left & $32.98 \pm 4.72$ & 31.69 & 34.27 & $20.09 \pm 4.7$ & 18.80 & 21.39 \\
\hline
\end{tabular}

Table 11 Descriptive analysis of pedicle diameter and height in study population $(N=45)$

\begin{tabular}{|c|c|c|c|c|c|c|}
\hline \multirow[t]{2}{*}{ Parameter } & \multirow{2}{*}{$\begin{array}{l}\text { Diameter } \\
\text { mean } \pm S D \\
(\mathrm{~mm})\end{array}$} & \multicolumn{2}{|c|}{$95 \% \mathrm{Cl}$} & \multirow{2}{*}{$\begin{array}{l}\text { Height } \\
\text { mean } \pm \text { SD } \\
(\mathrm{mm})\end{array}$} & \multicolumn{2}{|c|}{$95 \% \mathrm{Cl}$} \\
\hline & & Lower & Upper & & Lower & Upper \\
\hline L1 right & $5.87 \pm 0.79$ & 5.64 & 6.11 & $10.59 \pm 1.72$ & 10.07 & 11.10 \\
\hline L2 right & $6.24 \pm 1.03$ & 5.93 & 6.54 & $10.21 \pm 1.64$ & 9.72 & 10.70 \\
\hline L3 right & $7.47 \pm 1.73$ & 6.95 & 7.99 & $9.99 \pm 1.54$ & 9.52 & 10.45 \\
\hline L4 right & $8.88 \pm 1.74$ & 8.36 & 9.40 & $9.36 \pm 1.21$ & 9.00 & 9.72 \\
\hline L5 right & $11.09 \pm 1.58$ & 10.62 & 11.57 & $8.77 \pm 1.06$ & 8.45 & 9.09 \\
\hline L1 left & $5.95 \pm 0.76$ & 5.72 & 6.18 & $10.46 \pm 1.56$ & 10.00 & 10.93 \\
\hline L2 left & $6.19 \pm 1.03$ & 5.88 & 6.50 & $9.93 \pm 1.36$ & 9.52 & 10.34 \\
\hline L3 left & $7.42 \pm 1.58$ & 6.95 & 7.90 & $9.68 \pm 1.48$ & 9.24 & 10.13 \\
\hline L4 left & $8.75 \pm 1.92$ & 8.17 & 9.33 & $9.4 \pm 1.04$ & 9.09 & 9.71 \\
\hline L5 left & $10.79 \pm 1.54$ & 10.33 & 11.25 & $8.52 \pm 1$ & 8.21 & 8.82 \\
\hline
\end{tabular}


encountered by primary care physicians. After the invention of CT scan in 1991, there was a sudden revolutionary change in the medical management of low backache. It changed the perspective of the surgeons in terms of spinal surgeries and augmented the method of study of the lumbar spine anatomy noninvasively, making the decisions in terms of spinal instrumentation. For safe pedicle screws placement, knowledge of pedicle morphometry is compulsory because inconsistency between pedicle width and the screw diameter may lead to severe complications like nerve, vessel or visceral injuries.

Multidetector CT is the modality of choice for evaluation of detailed morphometry of spinal pedicles. The available lumbar morphometric normograms are of few parameters which are based on radiographs or cadaver and cannot be directly applied to plan surgical treatment. There has been reported data available from European countries using cadaveric measurements, but these measurements do not necessarily apply to the spine in the normal Indian population. ${ }^{9}$ Very few studies of CT morphometry are available in the Indian literature. Normal values for various pedicle dimensions by $\mathrm{CT}$ scan are lacking among the Indian population. Pedicle morphometric parameters show significant variations in different studies, which can be due to different characteristics of different populations studied.

Our study reveals pedicle dimension at all lumbar levels varying with age and heterogeneous ethnicity. It also shows that pedicles width in axial plane varies from 4.46 to $11.32 \mathrm{~mm}$ at L1-L5 levels in different age groups. The pedicles heights in the sagittal plane in our sample vary from 7.38 to $12.01 \mathrm{~mm}$ among the 10 to 90 years age group. Pedicles angulation in axial plane varies from 22.27 to 36.08 degree and lateral pedicle angulation in sagittal plane varies from 16.12 to 22.47 degree at L1-L5 levels among the 10 to 90 years age groups, respectively.

In the present study, the mean pedicle dimensions were greater than those mentioned by Signel et al and Arora et al at all lumbar levels. This difference between our study and that described by Signel et al and Arora et al study was due to large sample size, population of different age group, and inclusion of population of different ethnicity or racial difference. In our study, there was no statistically significant difference in the measured values in right and left side in both genders. ${ }^{10-12}$

Table 12 Descriptive analysis of pedicle body angulation transverse (TA) and sagittal in study population (N=45)

\begin{tabular}{|c|c|c|c|c|c|c|}
\hline \multirow[t]{2}{*}{ Parameter } & \multirow{2}{*}{$\begin{array}{l}\text { Axial } \\
\text { mean } \pm S D \\
(\mathrm{~mm})\end{array}$} & \multicolumn{2}{|c|}{$95 \% \mathrm{Cl}$} & \multirow{2}{*}{$\begin{array}{l}\text { Lateral } \\
\text { mean } \pm S D \\
(\mathrm{~mm})\end{array}$} & \multicolumn{2}{|c|}{$95 \% \mathrm{Cl}$} \\
\hline & & Lower & Upper & & Lower & Upper \\
\hline L1 right & $23.73 \pm 1.71$ & 23.21 & 24.24 & $17.95 \pm 3.3$ & 16.96 & 18.94 \\
\hline L2 right & $23.05 \pm 1.65$ & 22.55 & 23.55 & $17.52 \pm 3.24$ & 16.54 & 18.49 \\
\hline L3 right & $24.8 \pm 1.67$ & 24.30 & 25.31 & $16.75 \pm 1.99$ & 16.15 & 17.34 \\
\hline L4 right & $27.81 \pm 2.18$ & 27.16 & 28.47 & $16.6 \pm 2.62$ & 15.81 & 17.39 \\
\hline L5 right & $31.94 \pm 4.99$ & 30.44 & 33.44 & $17.4 \pm 4.91$ & 15.93 & 18.88 \\
\hline L1 left & $23.87 \pm 1.54$ & 23.41 & 24.34 & $17.95 \pm 3.1$ & 17.02 & 18.88 \\
\hline L2 left & $23.44 \pm 1.52$ & 22.98 & 23.90 & $17.57 \pm 3.22$ & 16.60 & 18.53 \\
\hline L3 left & $24.89 \pm 1.59$ & 24.41 & 25.37 & $16.88 \pm 1.97$ & 16.28 & 17.47 \\
\hline L4 left & $27.43 \pm 2.58$ & 26.65 & 28.20 & $16.68 \pm 2.83$ & 15.83 & 17.53 \\
\hline L5 left & $32.32 \pm 5.03$ & 30.80 & 33.83 & $17.57 \pm 4.9$ & 16.10 & 19.04 \\
\hline
\end{tabular}

Table 13 Descriptive analysis of pedicle diameter and height in study population $(N=30)$.

\begin{tabular}{|c|c|c|c|c|c|c|}
\hline \multirow[t]{2}{*}{ Parameter } & \multirow{2}{*}{$\begin{array}{l}\text { Diameter } \\
\text { mean } \pm S D \\
(\mathrm{~mm})\end{array}$} & \multicolumn{2}{|c|}{$95 \% \mathrm{Cl}$} & \multirow{2}{*}{$\begin{array}{l}\text { Height } \\
\text { mean } \pm \text { SD } \\
(\mathrm{mm})\end{array}$} & \multicolumn{2}{|c|}{$95 \% \mathrm{Cl}$} \\
\hline & & Lower & Upper & & Lower & Upper \\
\hline L1 right & $4.9 \pm 0.98$ & 4.54 & 5.27 & $10.03 \pm 1.39$ & 9.52 & 10.55 \\
\hline L2 right & $5.64 \pm 1.01$ & 5.26 & 6.02 & $10.2 \pm 1.4$ & 9.68 & 10.73 \\
\hline L3 right & $6.05 \pm 1.63$ & 5.44 & 6.65 & $9.77 \pm 1.24$ & 9.30 & 10.23 \\
\hline L4 right & $7.03 \pm 1.75$ & 6.37 & 7.68 & $8.27 \pm 1.45$ & 7.72 & 8.81 \\
\hline L5 right & $10.37 \pm 2.12$ & 9.58 & 11.16 & $7.77 \pm 1.7$ & 7.13 & 8.40 \\
\hline L1 left & $4.7 \pm 1.09$ & 4.29 & 5.10 & $10.1 \pm 1.45$ & 9.56 & 10.64 \\
\hline L2 left & $5.65 \pm 1.02$ & 5.27 & 6.03 & $10 \pm 1.41$ & 9.47 & 10.53 \\
\hline L3 left & $6.52 \pm 1.46$ & 5.97 & 7.06 & $9.81 \pm 1.09$ & 9.40 & 10.22 \\
\hline L4 left & $7.13 \pm 1.91$ & 6.42 & 7.84 & $8.23 \pm 1.34$ & 7.73 & 8.73 \\
\hline L5 left & $10.49 \pm 2.24$ & 9.65 & 11.33 & $7.73 \pm 1.59$ & 7.13 & 8.32 \\
\hline
\end{tabular}


Table 14 Descriptive analysis of pedicle body angulation transverse (TA) and sagittal in study population $(N=30)$.

\begin{tabular}{|c|c|c|c|c|c|c|}
\hline \multirow[t]{2}{*}{ Parameter } & \multirow{2}{*}{$\begin{array}{l}\text { Axial } \\
\text { mean } \pm S D \\
(\mathrm{~mm})\end{array}$} & \multicolumn{2}{|c|}{$95 \% \mathrm{Cl}$} & \multirow{2}{*}{$\begin{array}{l}\text { Lateral } \\
\text { mean } \pm \text { SD } \\
(\mathrm{mm})\end{array}$} & \multicolumn{2}{|c|}{$95 \% \mathrm{Cl}$} \\
\hline & & Lower & Upper & & Lower & Upper \\
\hline L1 right & $22.6 \pm 1.53$ & 22.02 & 23.17 & $18.44 \pm 1.44$ & 17.90 & 18.98 \\
\hline L2 right & $22.02 \pm 0.92$ & 21.68 & 22.36 & $16.54 \pm 1.52$ & 15.97 & 17.11 \\
\hline L3 right & $23.84 \pm 1.72$ & 23.20 & 24.48 & $16.04 \pm 1.29$ & 15.56 & 16.52 \\
\hline L4 right & $28.48 \pm 1.35$ & 27.98 & 28.99 & $17.36 \pm 1.82$ & 16.68 & 18.04 \\
\hline L5 right & $31.99 \pm 2.33$ & 31.12 & 32.86 & $15.56 \pm 3.14$ & 14.39 & 16.74 \\
\hline L1 left & $22.07 \pm 1.56$ & 21.49 & 22.65 & $18.77 \pm 1.47$ & 18.22 & 19.32 \\
\hline L2 left & $22.05 \pm 1.35$ & 21.54 & 22.55 & $17.03 \pm 1.46$ & 16.48 & 17.57 \\
\hline L3 left & $23.45 \pm 1.83$ & 22.77 & 24.14 & $16.46 \pm 1.38$ & 15.94 & 16.98 \\
\hline L4 left & $28.72 \pm 1.47$ & 28.17 & 29.26 & $17.43 \pm 1.81$ & 16.76 & 18.11 \\
\hline L5 left & $32.45 \pm 2.4$ & 31.55 & 33.35 & $15.83 \pm 2.79$ & 14.79 & 16.87 \\
\hline
\end{tabular}

Table 15 Descriptive analysis of pedicle diameter and height in study population $(N=14)$

\begin{tabular}{|c|c|c|c|c|c|c|}
\hline \multirow[t]{2}{*}{ Parameter } & \multirow{2}{*}{$\begin{array}{l}\text { Diameter } \\
\text { mean } \pm S D \\
(\mathrm{~mm})\end{array}$} & \multicolumn{2}{|c|}{$95 \% \mathrm{Cl}$} & \multirow{2}{*}{$\begin{array}{l}\text { Height } \\
\text { mean } \pm S D \\
(\mathrm{~mm})\end{array}$} & \multicolumn{2}{|c|}{$95 \% \mathrm{Cl}$} \\
\hline & & Lower & Upper & & Lower & Upper \\
\hline L1 right & $4.66 \pm 0.89$ & 4.14 & 5.17 & $9.78 \pm 1.25$ & 9.06 & 10.50 \\
\hline L2 right & $5.71 \pm 1.35$ & 4.93 & 6.50 & $10.15 \pm 1.16$ & 9.48 & 10.82 \\
\hline L3 right & $5.79 \pm 1.64$ & 4.84 & 6.73 & $9.44 \pm 0.45$ & 9.19 & 9.70 \\
\hline L4 right & $6.84 \pm 1.83$ & 5.78 & 7.89 & $7.95 \pm 0.73$ & 7.53 & 8.37 \\
\hline L5 right & $10.21 \pm 1.93$ & 9.09 & 11.32 & $7.49 \pm 1.63$ & 6.55 & 8.43 \\
\hline L1 left & $4.46 \pm 0.95$ & 3.91 & 5.02 & $9.49 \pm 1.2$ & 8.80 & 10.19 \\
\hline L2 left & $5.62 \pm 1.28$ & 4.88 & 6.36 & $9.89 \pm 1.06$ & 9.28 & 10.51 \\
\hline L3 left & $5.89 \pm 1.66$ & 4.93 & 6.85 & $9.44 \pm 0.38$ & 9.22 & 9.66 \\
\hline L4 left & $6.91 \pm 1.89$ & 5.81 & 8.00 & $7.56 \pm 0.91$ & 7.03 & 8.08 \\
\hline L5 left & $10.29 \pm 2.23$ & 9.00 & 11.58 & $7.38 \pm 1.57$ & 6.47 & 8.29 \\
\hline
\end{tabular}

Table 16 Descriptive analysis of pedicle body angulation transverse (TA) and sagittal in study population $(N=14)$.

\begin{tabular}{|c|c|c|c|c|c|c|}
\hline \multirow[t]{2}{*}{ Parameter } & \multirow{2}{*}{$\begin{array}{l}\text { Axial } \\
\text { mean } \pm S D \\
(\mathrm{~mm})\end{array}$} & \multicolumn{2}{|c|}{$95 \% \mathrm{Cl}$} & \multirow{2}{*}{$\begin{array}{l}\text { Lateral } \\
\text { mean } \pm \text { SD } \\
(\mathrm{mm})\end{array}$} & \multicolumn{2}{|c|}{$95 \% \mathrm{Cl}$} \\
\hline & & Lower & Upper & & Lower & Upper \\
\hline L1 right & $22.94 \pm 0.85$ & 22.45 & 23.43 & $18.44 \pm 0.88$ & 17.93 & 18.95 \\
\hline L2 right & $22.41 \pm 1.67$ & 21.45 & 23.38 & $16.81 \pm 1.89$ & 15.71 & 17.90 \\
\hline L3 right & $24.14 \pm 2$ & 22.98 & 25.29 & $16.13 \pm 1.52$ & 15.25 & 17.01 \\
\hline L4 right & $29.13 \pm 1.19$ & 28.44 & 29.82 & $17.4 \pm 0.98$ & 16.84 & 17.96 \\
\hline L5 right & $32.27 \pm 1.8$ & 31.23 & 33.31 & $16.12 \pm 3.21$ & 14.27 & 17.98 \\
\hline L1 left & $22.64 \pm 1.06$ & 22.03 & 23.25 & $18.69 \pm 0.81$ & 18.22 & 19.15 \\
\hline L2 left & $22.27 \pm 1.6$ & 21.35 & 23.20 & $17.42 \pm 1.73$ & 16.42 & 18.42 \\
\hline L3 left & $23.91 \pm 2.11$ & 22.69 & 25.13 & $16.4 \pm 1.38$ & 15.60 & 17.20 \\
\hline L4 left & $29.38 \pm 0.84$ & 28.89 & 29.86 & $17.64 \pm 1.04$ & 17.05 & 18.24 \\
\hline L5 left & $32.57 \pm 1.77$ & 31.55 & 33.59 & $16.4 \pm 2.8$ & 14.78 & 18.02 \\
\hline
\end{tabular}

Kang et al comparing pedicle diameter between the plain radiographs and CT scans in the lower thoracic and lumbar spinal levels (from T9 to L5) found that underestimation of the pedicle diameter in plain radiographs because of the fact that the maximum radiologic density of the pedicle is well within the true cortical margin of the pedicle due to complex transverse and sagittal pedicle angles at each spinal level. ${ }^{14,15}$ 
Table 17 Comparison of various lumbar spine pedicle parameters ( $\mathrm{mm}$ ) (literature comparison with present study)

\begin{tabular}{|l|l|l|l|l|l|l|l|l|}
\hline & Vertebra & Amonoo-Kuofi1 & \multicolumn{2}{l|}{ Singel et al ${ }^{11}$} & \multicolumn{2}{l|}{ Arora et al ${ }^{10}$} & \multicolumn{2}{l|}{ Present study } \\
\hline & Male & Female & Male & Female & Male & $\begin{array}{l}\text { Female } \\
\text { right }\end{array}$ & Left \\
\hline L1 width & 10.3 & 8.7 & 8.2 & 8.5 & 7.51 & 7.49 & 5.88 & 5.84 \\
\hline L1 height & 19.4 & 16.3 & 14.7 & 15.5 & 14.79 & 14.34 & 11.01 & 10.89 \\
\hline L2 width & 10.7 & 9 & 8.5 & 8.75 & 7.95 & 7.91 & 6.52 & 6.50 \\
\hline L2 height & 18.9 & 15.3 & 15 & 14.5 & 15.42 & 15.04 & 10.46 & 10.23 \\
\hline L3 width & 12.1 & 10.5 & 10.4 & 10.6 & 8.75 & 8.7 & 17.89 & 7.88 \\
\hline L3 height & 19.3 & 15.9 & 14.7 & 14.8 & 16.42 & 15.6 & 10.12 & 9.85 \\
\hline L4 width & 13 & 11.1 & 13.5 & 13.8 & 13 & 12.97 & 9.10 & 8.97 \\
\hline L4 height & 19.9 & 16.1 & 14 & 14 & 17.48 & 17.11 & 9.53 & 9.33 \\
\hline L5 width & - & - & - & - & - & - & 11.92 & 11.53 \\
\hline L5 height & - & - & - & - & - & - & 9.00 & 8.85 \\
\hline
\end{tabular}

In a study by Chadha et al, the subset of patients was from the Indian subcontinent, where they have calculated morphometry values from T9 till S1. Our study differs from this study in the sense that all our parameters were evaluated on work station and not on films which may not be the correct methods of measurement. Furthermore, to calculate the sagittal angulation oblique, images were created at the workstation. Our study tries to bring out the data for spinal pedicle morphometry at L1 to L5 levels and at different age groups. ${ }^{16}$

In a study by Acharya et al, the authors included lower thoracic and all lumbar vertebrae. In their study, a total of 50 patients were included. In our study, a total of 321 participants were included and hence the accuracy of data, as per age stratification, is likely to be more accurate. ${ }^{17}$

Transpedicular spinal fixation has gained importance these days throughout the world but there is requirement of precise knowledge of morphology of pedicles and its relation with neural structures for safe and efficient surgery. The strength of the stabilized segment will depend upon the soundness of the screw fixation within the pedicles and the design of the fixation system.

Lee et al showed 98\% accuracy in transpedicular screw fixation using the intraoperative CT navigation system in stabilizing unstable thoracolumbar spine fractures. A misplaced transpedicular screw could be revised immediately during real-time confirmation of the transpedicular screw position, hence preventing second revision surgery. The intraoperative CT navigation system provided an accurate and safe alternative for management of unstable thoracolumbar spine fractures. ${ }^{18}$

Presently, CT is the modality of choice for computing various measurements for transpedicular fixation. Hence, based on all observations, preoperative CT imaging with as thinner slices as possible is recommended for more accurate assessment of the morphometric characteristics of the lumbar pedicle and the placement of the screws.

\section{Conclusions}

- Multidetector CT imaging is the noninvasive modality of choice for evaluation of detailed morphometry of spinal pedicles and helps in making the decisions in terms of spinal instrumentation.

- Our study is the first of its kind based on a large population with different age groups (18-90 years), as per the review of literature, to provide details of lumbar spinal pedicle morphometry from the Indian subcontinent.

\section{Conflict of Interest}

None declared.

\section{References}

1 Ramamurthi B, Tandon PN, eds. Textbook of Neurosurgery. 2nd ed. New Delhi: BI Churchill Livingstone; 1996

2 Watkins RG, Surgical Approaches to the Spine. New York: Springer Verlag; 1983

3 Zindrick MR, Wiltse LL, Doornik A, et al. Analysis of the morphometric characteristics of the thoracic and lumbar pedicles. Spine 1987;12(2):160-166

4 Whitecloud TS III, Butler JC, Cohen JL, Candelora PD. Complications with the variable spinal plating system. Spine 1989;14(4):472-476

5 Alfonso Olmos M, Villas Tomé C, Beguiristain Gúrpide JL, ZubietaZárraga JL. Morfometría vertebral en población española. Rev. ortop. TraumatolMadr., Ed. impr. 2002;46(2):158:64

6 Okutan O, Kaptanoglu E, Solaroglu I, Beskonakli E, Tekdemir I. Determination of the length of anteromedial screw trajectory by measuring interforaminal distance in the first sacral vertebra. Spine 2004;29(15):1608-1611

7 Rosselló JF, Estela GR, Jaume MR, Comamala ML. Injury to the gonadal, renal and duodenal veins during pedicle screw extraction surgery. Revista española de cirugía ortopédica y traumatologíaEnglish edition 2009;53(5):340:3 
8 Morales-Alvoes R, Galindo-Aguilar U, Martínez-García, JE, et al. Morphometric assessment of the lumbar pedicle isthmus by reformatted CT: variations according to age and gender. Eur J Anat 2015;19(3):277-286

9 Kim NH, Lee HM, Chung IH, Kim HJ, Kim SJ. Morphometric study of the pedicles of thoracic and lumbar vertebrae in Koreans. Spine 1994;19(12):1390-1394

10 Singel TC, Patel MM, Gohil DV. A study of width and height of lumbar pedicles in Saurashtra region. J Anat Soc India 2004;53(1):4-9

11 Arora L, Dada R, Singh V. Morphometric study of lumbar pedicles in Delhi region of northern India. Indian J Practising Doctor. 2005;3(5):11-12

12 Amonoo-Kuofi HS. Age-related variations in the horizontal and vertical diameters of the pedicles of the lumbar spine. J Anat 1995;186(Pt 2) :321-328

13 Chawla K, Sharma M, Abhaya A, Kochhar S. Morphometry of the lumbar pedicle in North West India. Eur J Anat 2011;15(3):155-161
14 Kang KS, Song KS, Lee JS, Yang JJ, Song IS. Comparison of radiographic and computed tomographic measurement of pedicle and vertebral body dimensions in Koreans: the ratio of pedicle transverse diameter to vertebral body transverse diameter. Eur Spine J 2011;20(3):414-421

15 Robertson PA, Stewart NR. The radiologic anatomy of the lumbar and lumbosacral pedicles. Spine 2000;25(6):709-715

16 Chadha M, Balain B, Maini L, Dhaon BK. Pedicle morphology of the lower thoracic, lumbar, and S1 vertebrae: an Indian perspective. Spine 2003;28(8):744-749

17 Acharya S, Dorje T, Srivastava A. Lower dorsal and lumbar pedicle morphometry in Indian population: a study of four hundred fifty vertebrae. Spine 2010;35(10):E378-E384

18 Lee CY, Wu MH, Li YY, et al. Intraoperative computed tomography navigation for transpedicular screw fixation to treat unstable thoracic and lumbar spine fractures: clinical analysis of a case series (CARE-compliant) Medicine (Baltimore) 2015;94(20):e757 